\title{
Molecular Dynamics Simulation of Human Pancreatic Lipase and Lipase-colipase Complex: Insight into the Structural Fluctuations and Conformational Changes
}

\author{
Sikiru Akinyeye Ahmed ${ }^{1,}$, Nizakat Ali $^{2}$, Urooj Qureshi ${ }^{2}$, Ruqaiya Khalil ${ }^{2}$, Zaheer-Ul Haq Qasmi ${ }^{2}$ \\ ${ }^{1}$ Department of Chemistry, Kwara State University, Malete, Ilorin, Nigeria \\ ${ }^{2}$ International Centre for Chemical and Biological Sciences (ICCBS), University of Karachi, Karachi, Pakistan
}

Email address:

akinyeye.ahmed@kwasu.edu.ng (S. A. Ahmed)

${ }^{*}$ Corresponding author

\section{To cite this article:}

Sikiru Akinyeye Ahmed, Nizakat Ali, Urooj Qureshi, Ruqaiya Khalil, Zaheer-Ul Haq Qasmi. Molecular Dynamics Simulation of Human Pancreatic Lipase and Lipase-colipase Complex: Insight into the Structural Fluctuations and Conformational Changes. International Journal of Computational and Theoretical Chemistry. Vol. 8, No. 1, 2020, pp. 19-26. doi: 10.11648/j.ijctc.20200801.13

Received: January 25, 2020; Accepted: February 17, 2020; Published: February 28, 2020

\begin{abstract}
Although the structure of Human Pancreatic Lipase has been documented through the X-ray crystallography, the knowledge about the molecular rearrangement and dynamic equilibrium in the structure (particularly in the catalytic triad and lid domains) is very scanty. The structural fluctuations and conformational changes undergo by Human Pancreatic Lipase (HPL) with and without colipase were computationally investigated through molecular dynamics simulation technique using GROMACS 2018.4, MOE 2016.0801 and VMD softwares in order to gain insight into the complex transitions at different domains. The structural stability was revealed vis-a-vis Root Mean Square Deviation (RMSD) and Root Mean Square Fluctuations (RMSF) plots. The levels of compactness/folding and conformational changes of the protein were determined using Radius of gyration and secondary analysis respectively. Salt bridge analysis gives more ionic pairs interactions than experimentally determined results. Results show that though both proteins are stable, lipase-colipase complex is more deviated and flexible than lipase. Also, additional information regarding the conformational transitions, interactions and dynamics that govern stability of lipase-colipase complex which were 'hidden' to experimental techniques were revealed.
\end{abstract}

Keywords: Human Pancreatic Lipase, Conformational Change, RMSD, Radius of Gyration

\section{Introduction}

Human Pancreatic lipase is one of the key enzymes in the hydrolysis of triglycerides into monoglycerides and free fatty acid, and is thus considered a promising target for the treatment of obesity [1]. Structurally, human pancreatic lipase is a glycoprotein containing 449 amino acid residues $[2,3]$ and it consists of two distinct domains; a large Nterminal domain (residue 1-336) comprising the active site (hydrophobic), and a smaller C-terminal domain (residues 337-449) having a $\beta$-sandwich fold that forms the main binding sites for the colipase [2, 4-6]. The N-terminal domain consisting of a $\alpha / \beta$-hydrolase fold contains the catalytic site. A surface loop formed lid, delineated by a disulphide bond between residue Cysteine 237 and Cysteine 261 covers the active site and controls the activity of Human Pancreatic
Lipase [5]. The lid that sterically hinders access of substrate to the active site of the enzyme when it attains inactive conformation opens and configures the active site when it is in active conformation [7]. Colipase is a small protein $(\approx 10-$ $11 \mathrm{kDa})$ cofactor needed by pancreatic lipase for efficient dietary lipid hydrolysis; it is fairly flat, and composed of 95 amino acid residues $[3,5]$. The activated form is shorter than the procolipase from which five amino acids have been removed by trypsin [3]. This pentapeptide is called enterostatin and it is believed to play a role in satiety regulation and fat intake [8].

Literature reports on the previous models done by some researchers indicate that colipase binds exclusively to the Cterminal $\beta$-sheet domain, extending over more than $50 \AA$ and thus generating a hydrophobic plateau $[5,9]$. This association engenders a shift of the lid and $\beta 5$-loop, so that the 
hydrophobic 39 -loop open and the oxyanion hole is created [10]. The catalytic N-terminal domain is brought in close contact with the lipid-water interface, the active site thus becoming exposed to lipolytic substrates. The hydrophobic plateau ensures a strong interaction between the lipasecolipase complex and the lipid-water interface. However, the conformation change is not induced in the absence of an interface [9, 11]. Egloff et. al. [12] reported that before the formation of Pancreatic Lipase-Colipase complex, Pancreatic Lipase binds to the lipid and this causes conformational changes at the heterodimeric interface of Pancreatic Lipase which in turn facilitate the interaction with the Colipase. Bourne et. al. [13] submitted that the entire activity of the enzyme is maintained by the catalytic triad (comprising Ser152, Asp176 and His263) in the active pocket of the protein. Colipase therefore reduces the competition for the interface with other substances (e.g. Bile salt and phospholipids), in favour of pancreatic lipase, by expanding the hydrophobic area of the latter [14]. Brockman's work goes further by showing evidence of the colipase ability to reorganize the interface and thus to concentrate lipolysis reactants in its vicinity [15].

The application of molecular dynamics simulations to very large and complex molecules such as protein and enzymes has been of tremendous benefits to the Biochemists and Structural biologists because of its capacity to reveal information beyond what is available in the static structures deposited in the Protein Data Bank [16, 17]. Several work on molecular dynamics simulations have been carried out to get more insight into the lid rearrangements of different lipases. For instance, Aloulou et al., applied molecular dynamics simulation to investigate phosphatidylcholine (PC) binding modes within the catalytic cavity of Porcine Pancreatic Lipase (PPL) and human pancreatic lipase (HPL) [18]. Barbe et al., have used robotic-based approach to simulate large-scale "open-toclosed" movement of Burkholderia cepacia lipase lid [19]. James et. al., used molecular dynamics simulations to study the hydrolysis of ibuprofen esters by Candida rugosa lipase (CPL) from the crystallographic coordinates of the open form of the enzyme under acidic and neutral conditions [20] Selvan et. al., performed molecular dynamics simulations of human and dog gastric lipases under acidic and neutral conditions to study the domain movement of these enzymes [21].

In this work, a 70ns atomistic molecular dynamics simulation time frame was performed on closed lid form of human pancreatic lipase-colipase complex to gain insight into the structural and conformational changes, binding interactions and dynamics that govern its stability.

\section{Computational Methodology}

\subsection{Starting Structures}

The crystal structure of the Human Pancreatic Lipase (HPL) complexed with cofactor procolipase and solved to
$3.04 \AA$ resolutions (PDB code: $1 \mathrm{~N} 8 \mathrm{~S}$ ) [22] was obtained from the Protein Data Bank [23]. In this structure, the activator colipase (chain $\mathrm{C}$ ) was removed for the simulation of HPL only whereas both chains $\mathrm{A}$ and $\mathrm{C}$ in $1 \mathrm{~N} 8 \mathrm{~S}$ were intact for the lipase-colipase simulations.

\subsection{Molecular Dynamics Simulation}

GROMACS 2018.4 software [24-26] was used for the molecular dynamics simulation of both systems (i.e. Lipase and lipase-colipase complex). In human pancreatic lipasecolipase complex, the first five residues (501-505) and the last five (591-595) on the chain C (i.e. colipase) were missing in crystal structure and were modelled using MOE 2016.0801 [27]. The system was solvated with an extended simple point charge model (SPC/E) [25] water, in a cubic box which left $1.0 \mathrm{~nm}$ space around the solute. All bonds were constraints with All-atom Automatic Optimized Parameters for Liquid Simulations OPLS-AA/L [28] force field. Counter ions in the form of $3 \mathrm{Na}^{+}$ions were added to neutralise the two systems. A steepest descents algorithm was used to minimize the energy of each system and to relax the solvent molecules. System equilibration was done for $1000 \mathrm{ps}$ in NVT and NPT ensembles at $300 \mathrm{~K}, 1.05$ bar and average density of $998.3 \mathrm{~kg}$ $\mathrm{m}^{-3}$. The energy minimized structures were subjected to a position restraint molecular dynamics simulation for $70 \mathrm{~ns}$. GROMACS built in tools; g_rms, g_rmsf, and g_gyrate were used to compute Root Mean Square Deviation (RSMD), Root Mean Square Fluctuations (RSMF) and radius of gyration. Secondary structure and salt bridge analysis were done using VMD. For visual analysis, the trajectories were aligned on the initial structures using VMD. All graphs were visualized by a $2 \mathrm{D}$ plotting tool called Xmgrace and the images of superimposed structures were obtained using VMD software [29].

\section{Results and Discussion}

\subsection{Rmsd and Rmsf Analysis}

Figure 1a shows the backbone RMSD plots of lipase and lipase-colipase complex for the 70ns simulation. The sharp increase in the backbone deviation at $0.16 \mathrm{~nm}$ and $0.22 \mathrm{~nm}$ for only Lipase and Lipase-colipase complex respectively was observed up to 10ns course of simulation. After 10ns, Lipasecolipase complex showed marked deviation up to $0.35 \mathrm{~nm}$ and for Lipase deviated up to $0.25 \mathrm{~nm}$. The deviation increased progressively to $0.4 \mathrm{~nm}$ for Lipase-colipase complex and $0.3 \mathrm{~nm}$ for lipase at 30ns. Maximum deviation occurred at 50ns and this continues till 70ns. However, after 50ns, the RMSD plots of both Lipase and Lipase-colipase complex clustered together there were no observable differences. After the deviation to $0.32 \mathrm{~nm}$ observed in between $50 \mathrm{~ns}$ and $60 \mathrm{~ns}$ in the Lipasecolipase complex, both proteins retain their stability till the end of simulation time frame.

We observed higher deviation in the lipase-colipase complex as compared to lipase (apo), which shows that the complex is more flexible than the lipase (apo). In the lipase, 
the regions between residues His203-Gly216, Cys237-Cys261, and Met397-Arg414 show varying degree of fluctuations during the MD simulation (figure 1b). The highly fluctuated residues in the colipase are in the regions between Asn526Cys539, Ser547-Glu564 and Leu567-Cys587. Very high fluctuations observed in these residues in the colipase support the hypothesis of the three finger-shaped regions held together by disulphide bridges proposed by van Tilbeurgh et. al. [22]. Further these regions belong to the loop region of the Lipasecolipase enzyme. For instance, the residues Cys237-Cys261 is a surface loop (that form the lid domain) covering the active sites of the enzyme. The residues Gly76-Trp85 and His203Gly216 form the $\beta 5$ and $\beta 9$ loops respectively and both played prominent roles in the open and close lid conformations. Also, residues Met397-Arg414 is the 35 ' loop (hydrophobic loop) of the C-terminal of lipase orients in same plane as the hydrophobic plateau of colipase and the lid [7, 30]. The fluctuations in the residues Glu515-Cys523 was due to the supposedly shorter and detached fourth finger formed between the N-terminal and $\beta$-strand [22]. Since, the loop region tends to be more flexible than other part of protein, it can be inferred that high fluctuations in the RMSF of a few part of protein is caused by the loop structures.

RMSD

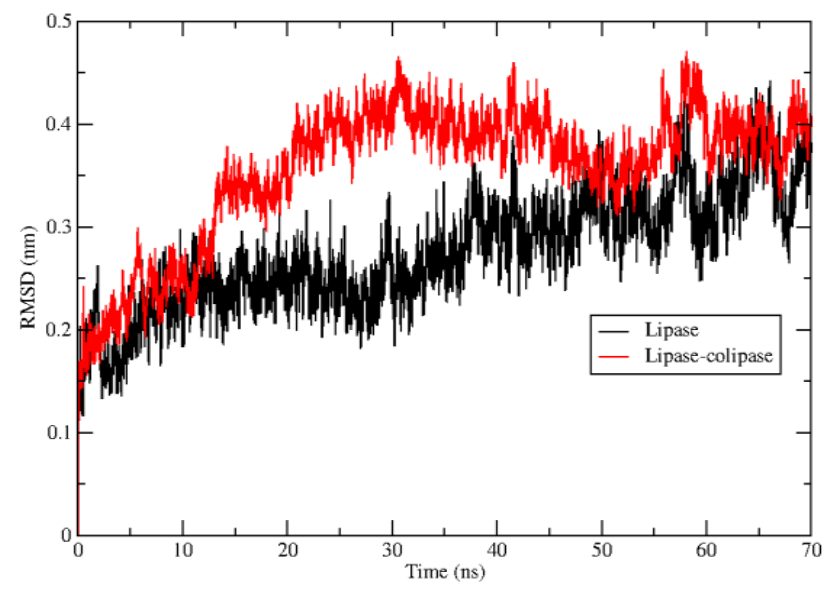

(a)

RMS fluctuation

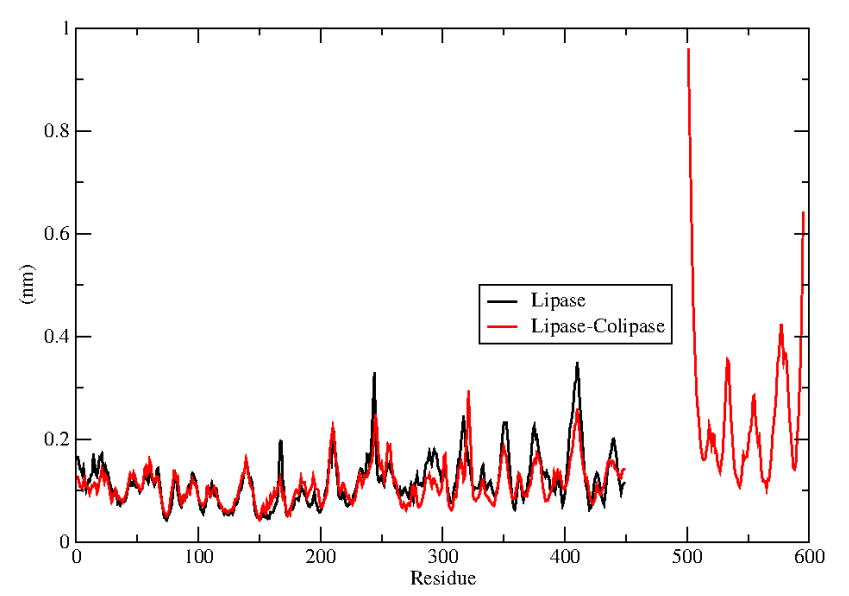

(b)

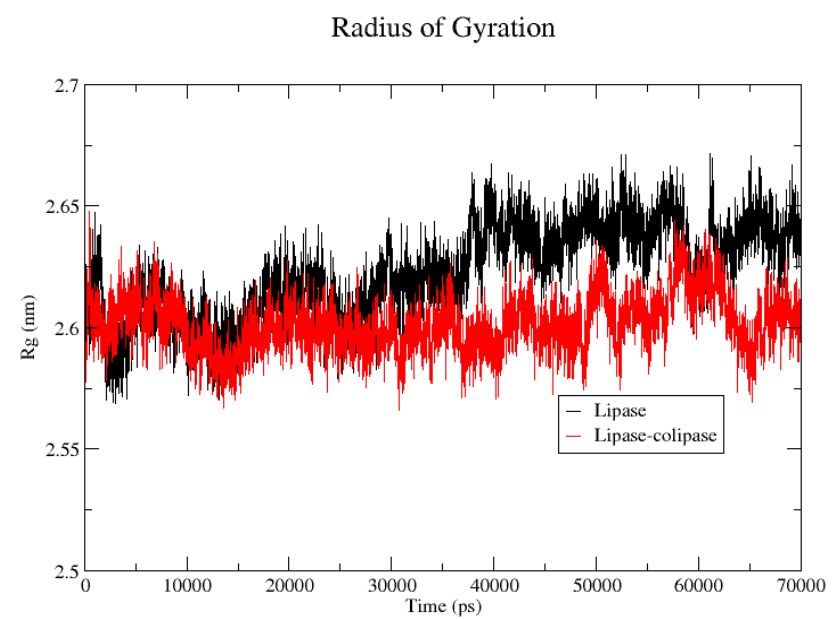

(c)

Figure 1. (a) The backbone RMSD plots of lipase and lipase-colipase complex. (b) The backbone RMSF plots of lipase and lipase-colipase complex (c) Radius of gyration as a function of time.

The radius of gyration of the two simulated structures is given against the simulated time in figure 1c for comparative illustration. The result shows that during the evolution of the trajectories, the centres of mass of the two systems are stable and compact throughout the simulation period with overall fluctuations of $2.61-2.63 \mathrm{~nm}$. The values of radius of gyration for the lipase-colipase structure fluctuate around $2.6 \mathrm{~nm}$ throughout the simulation, while that of the lipase structure fluctuate arround $2.63 \mathrm{~nm}$. Since radius of gyration determines the protein structure compactness/folding, it is convenient to infer that lipase is less tightly packed because of high value of its radius of gyration as proposed by Galzitskaya and Garbuzynskiy [31-33].

\subsection{Secondary Structure Analysis}

Results of secondary structure analysis of the conformational changes at the active sites, the lid domain and in other loops (i.e. $\beta 5$ and $\beta 9$ loops) associated with the restructuring of the lid are presented in figures $2-5$. In the lid domain, the conformational change observed in the secondary structure motifs was from $\alpha$-helix to turn between the residues Ile248 and Gly254 in the lipase-colipase complex (figure $2 \mathrm{~b}$ ) contrary to the experimentally reported conformational change between the residues Ile 248 and Thr255 [5]. No conformational change in the secondary structure was observed in the only lipase system (figure 2a). Also, figure 2 shows the residues Ile241-Val246 and Arg256Ala260 in both systems were not extended conformation in the closed lid as reported in the literature [5], rather they are coil.

It has been hypothesized $[5,34]$ that the lid in the closed form makes few contacts with the other regions of the protein that border the catalytic pocket (notably the $\beta 5$ and $\beta 9$ loops) and this interaction induces a spatial reorganization in their structural conformation. Figures 3 and 4 show that only $\beta 5$ surface loop adopt a totally different conformation from helix to coil at residues Glu82-Trp85 while $\beta 9$ loop remained 
unchanged in both the lipase-colipase complex and only lipase. This is in agreement with the experimentally reported results [5].

In figure 5 , it is evident that the combined conformational changes in the secondary structure of the lid and $\beta 5$ loop have changed the conformation of the three residues that form the catalytic triad. Ser152 changed from turn into $\beta$ strand, Asp176 and His263 changed from coil to $\beta$ anti- strand and $\alpha$-helix to turn respectively. Finally, the result of the hydrophobic $\beta 5$ ' loop (loop oriented towards lipid-water interface) as presented figure 6 shows no conformational changes in the secondary structures both in lipase-colipase complex and only lipase. This is not unconnected to the fact there is no lipid-water interface in this system to interact with the $\beta 5$ ' loop [22]

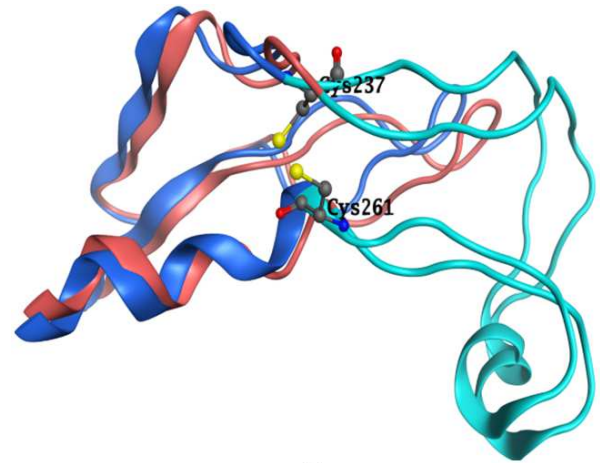

(a)

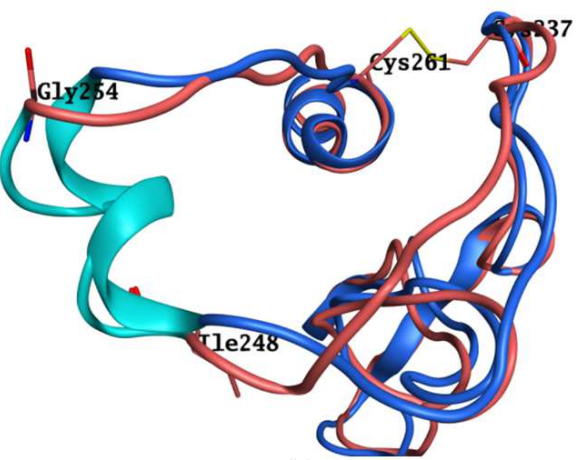

(b)

Figure 2. Conformational change in the secondary structures of the lid domain in (a) Lipase and (b) Lipase-colipase. Blue and pink colour ribbons connote before and after simulation respectively, the lid residues are in cyan colour.

The conformational change observed both in the lid and active site domain is suggestive of the possibility that there may exists a dynamic equilibrium between the open and closed lid forms. This assertion was made based on experimental reports that a few water molecules located between the lid and the surfaces of the catalytic crevices contribute to the transition state stability of the closed lid conformation [11] and crystallographic evidence that part of the $\beta 9$ loop, which stabilizes the lid domain in the closed conformation of the classical HPL, is totally exposed to the solvent, thereby making the catalytic Serine152 fully accessible to solvent [35].

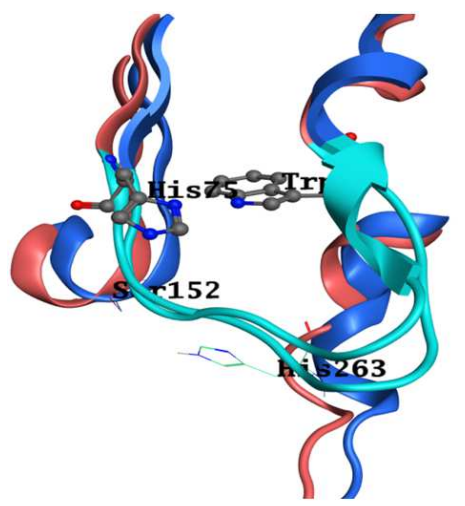

(a)

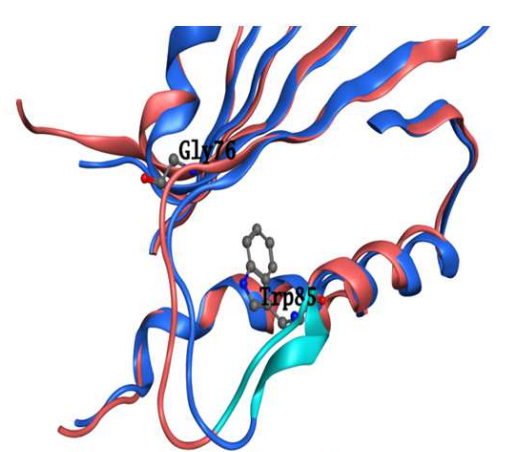

(b)

Figure 3. Conformational change in the secondary structures of the $\beta 5$ loops in (a) Lipase and (b) Lipase-colipase. Blue and pink colour ribbons connote before and after simulation respectively, the $\beta 5$ loops residues are in cyan colour.

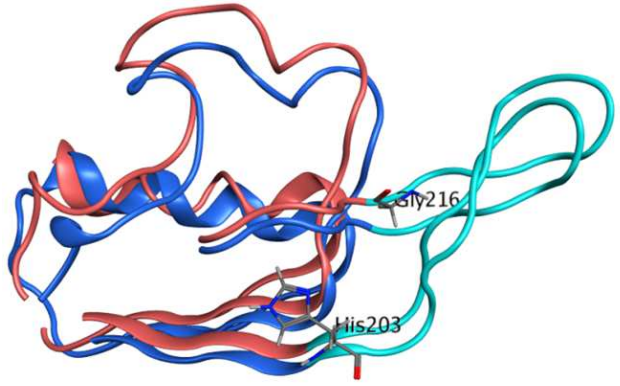

(a)

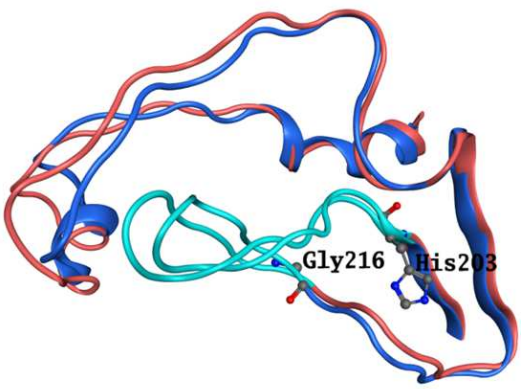

(b)

Figure 4. Conformational change in the secondary structures of the $\beta 9$ loops in (a) Lipase and (b) Lipase-colipase. Blue and pink colour ribbons connote before and after simulation respectively, the $\beta 9$ loop residues are in cyan colour. 


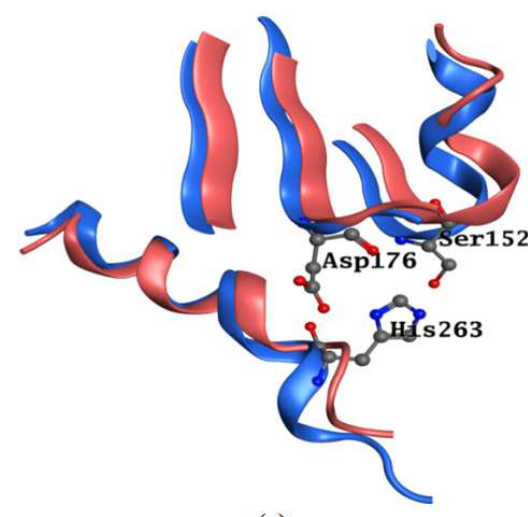

(a)

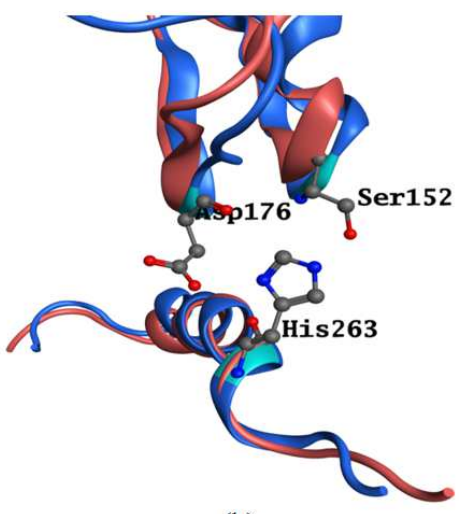

(b)

Figure 5. Conformational change in the secondary structures of the active site residues in (a) Lipase and (b) Lipase-colipase. Blue and pink colour ribbons connote before and after simulation respectively, the active site residues are in cyan colour.

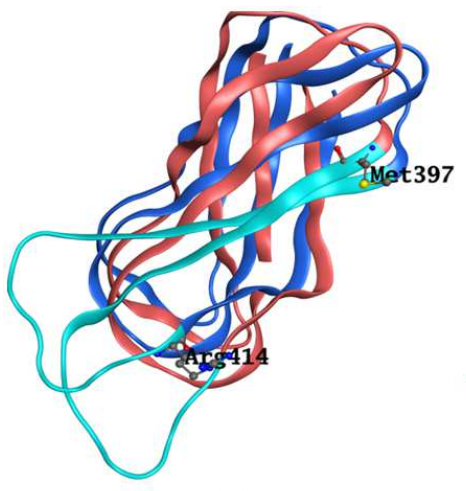

(a)

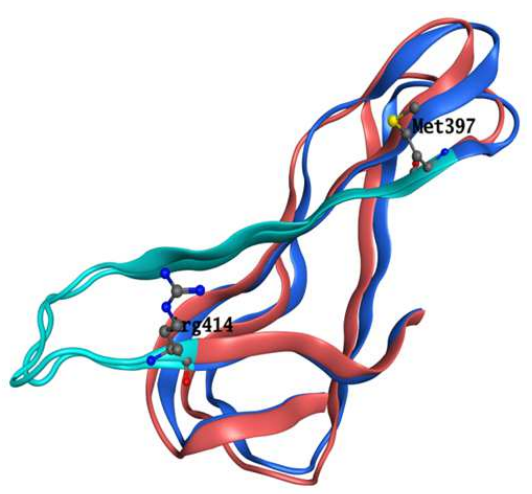

(b)

Figure 6. Conformational change in the secondary structures of the $\beta 5$ ' loops in (a) Lipase and (b) Lipase-colipase. Blue and pink colour ribbons connote before and after simulation respectively, the $\beta 5^{\prime}$ loop residues are in cyan colour.

\subsection{Salt Bridges Analysis}

Salt bridges (or charge-assisted hydrogen bond) in proteins are bonds between oppositely charged residues that are sufficiently close to each other to experience electrostatic attraction and it plays important roles in the conformational stability of proteins [36]. We reported the salt bridge formations in a number of residues between lipase and colipase in figures 7 (a)-(f). Three salt bridge interactions formed between Asp389 and Arg544 atoms are 2.70 (-O$\mathrm{HN}), 2.75 \AA\left(=\mathrm{O}-\mathrm{NH}_{2}\right)$ and $2.89 \AA\left(-\mathrm{O}-\mathrm{H}_{2} \mathrm{~N}\right)$. Similarly, Glu441 of lipase formed salt bridge with Arg565 with two distances $2.67 \AA\left(-\mathrm{O}-\mathrm{NH}_{2}\right)$ and $2.73 \AA\left(=\mathrm{O}-\mathrm{NH}_{2}\right)$. These are the two literature reported salt bridges pairs present in the crystal structure in lipase-colipase complex [22]. In contrast, six salt bridge interactions between lipase and colipase atoms were obtained in this study ffigure $7(a)-(f)\}$. The additional four short bridges \{figure $7(c)-(f)\}$ are between the atoms of Glu513-Lys367, Glu515-Lys238, Glu370-Lys524 and Glu545-Lys399. Detail of the salt bridge interactions between residues and distance between the linking atoms are presented in table 1 .

In addition, the number of salt bridges pairs in lipasecolipase complex is more than in lipase; simulated lipasecolipase complex has 63 salt bridge pairs while lipase has 52 .
This confirms the fact that there are more interactions in the complex than in only the lipase and also confers more stability on the complex [5]. The observed discrepancies in the number of salt bridges pairs experimentally reported and those reported in this work may be attributed to the ionization properties of the participating groups, which are significantly influenced by the protein environment [36]. Furthermore, the numbers of pairs may vary based on fact that salt bridges pairs do experience thermal fluctuations, continuously break and re-form, and their lifespan in solution is governed by the flexibility of the protein $[37,38]$.

Table 1. Salt bridge interactions between residues and distance between linking atoms.

\begin{tabular}{llll}
\hline S/N & Residue number & Linking atoms & Distance $(\AA)$ \\
\hline & & $-\mathrm{O}-\mathrm{HN}-$ & 2.70 \\
1. & \multirow{2}{*}{ Asp389-Arg544 } & 2.75 \\
& & $=\mathrm{O}-\mathrm{NH}_{2}$ & 2.89 \\
& & $-\mathrm{O}-\mathrm{H}_{2} \mathrm{~N}$ & 2.67 \\
2 & Glu441-Arg565 & 2.73 \\
3 & Glu513-Lys367 & $-\mathrm{O}-\mathrm{NH}_{2}$ & 4.27 \\
4 & Glu515-Lys238 & $-\mathrm{O}-\mathrm{NH}_{2}$ & 2.77 \\
5 & Glu370-Lys524 & $-\mathrm{O}-\mathrm{NH}-$ & 5.22 \\
6 & Glu545-Lys399 & $-\mathrm{O}-\mathrm{NH}-$ & 4.20 \\
\hline
\end{tabular}

adenotes the literature reported data [22], ${ }^{\mathrm{b}}$ denotes reported findings in this work. 


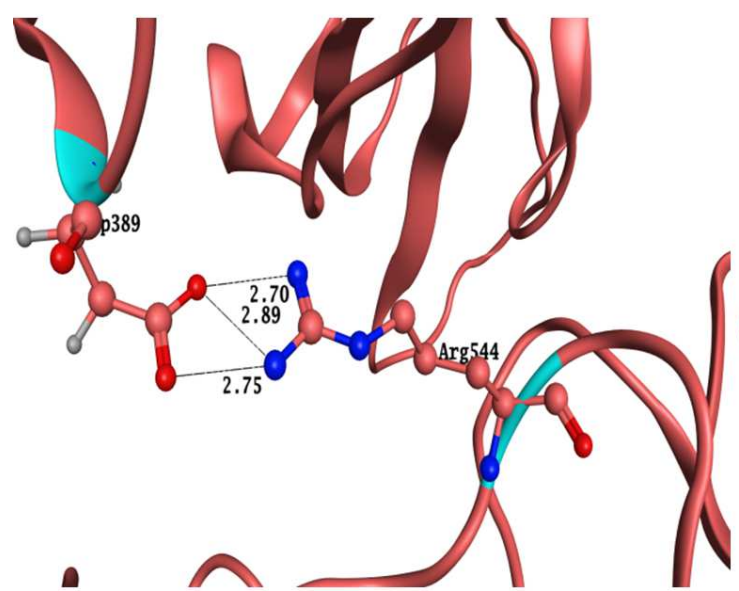

(a)

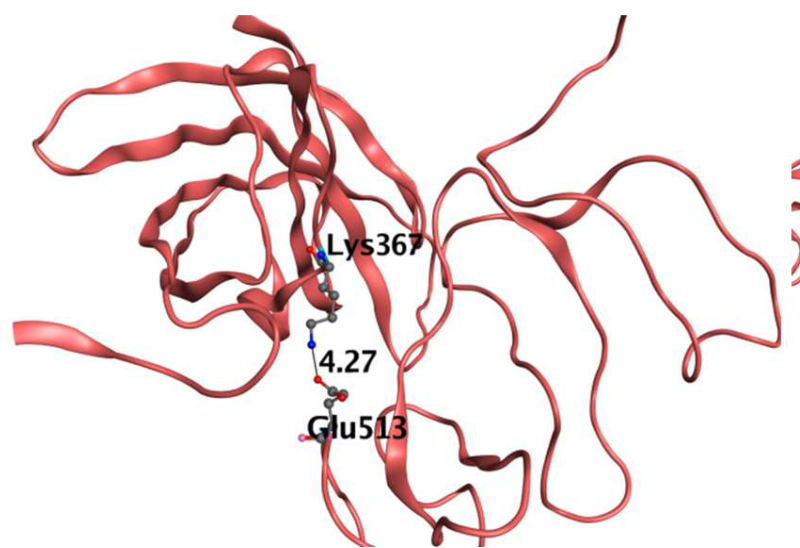

(c)

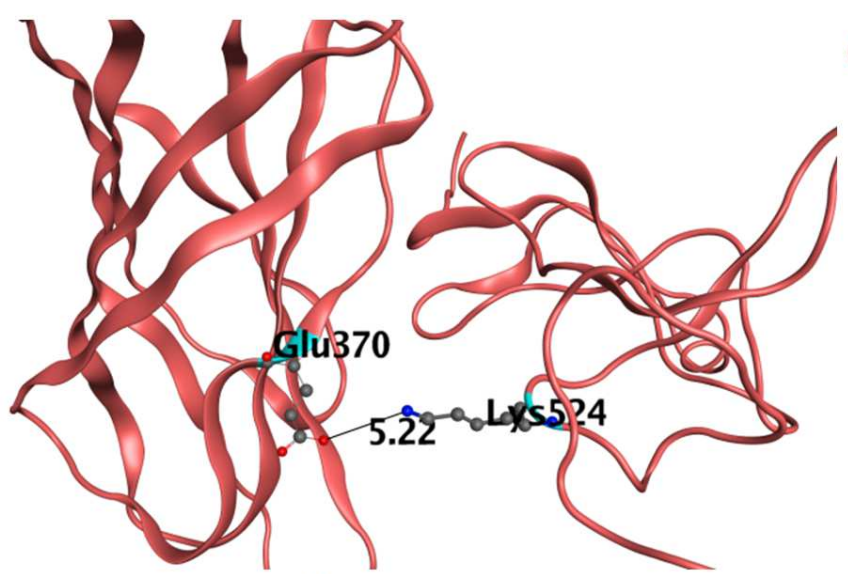

(e)

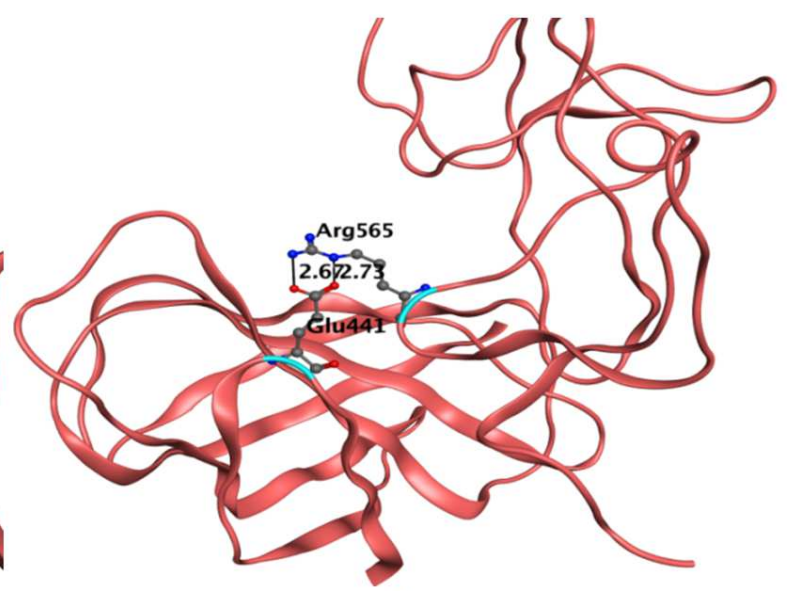

(b)

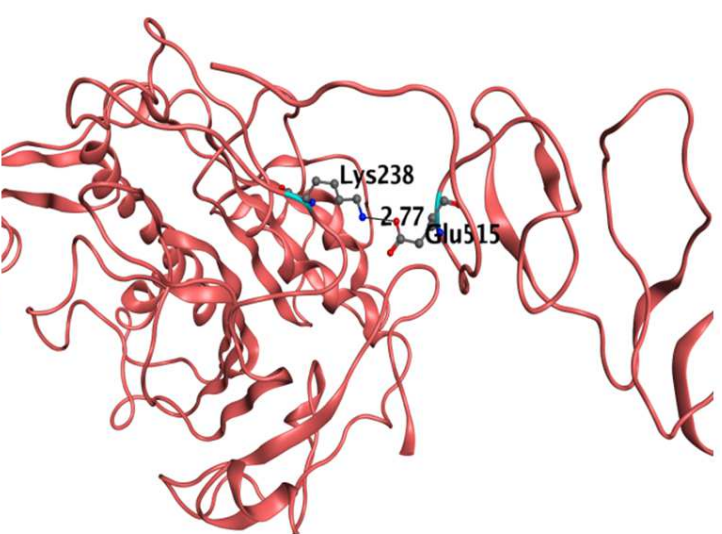

(d)

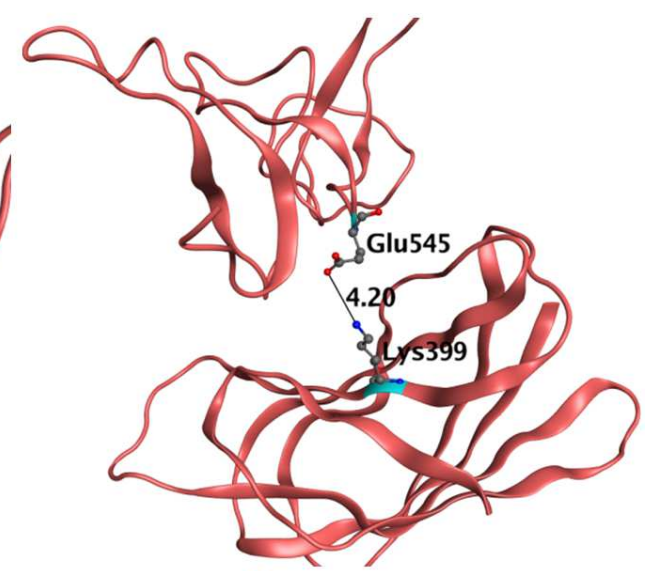

(f)

Figure 7. Salt bridges pairs between (a) Asp389 and Arg544 (b) Glu441 and Arg565 (c) Lys367 and Glu513 (d) Lys238 and Glu515 (e) Glu370 and Lys524 (f) Lys399 and Glu545.

\section{Conclusion}

By employing molecular dynamics simulations, the present study has revealed information beyond what is available in the static structures deposited in the Protein Data Bank. Additional information has been given regarding the conformational transitions, interactions and dynamics that govern stability of lipase-colipase complex which were 'hidden' to experimental technique. Also, this study gained insight into the numbers of underreported salt bridges in the crystallography and discovered more salt bridge interactions that were obscured in the literature. Though the system we studied is closed form, we have given the molecular details of the dynamic reorganization and transformation between 'closed lid' and 'open lid' forms through conformational changes in the secondary structures of the active site and the lid domains. Finally, despite the fact that the crystal structure lacks the micelle binding to the colipase, the conformational changes induced by colipase on the active site residues and lid domains were observed and reported. 


\section{Acknowledgements}

The authors acknowledge the support of the Third World Academy of Science (TWAS) and International Centre for Chemical and Biological Sciences (ICCBS), Karachi for the Postdoctoral Fellowship (FR number: 3240293180) given to S. A. Ahmed. Also, RK acknowledge the financial support from Higher Education Commission (10.13039/501100004681) under Indigenous $5000 \mathrm{PhD}$. Scholarship Program (Pin: 2BM2-215) and International Research Support Initiative Program (Pin: IRSIP 36 BMS 23). We also appreciate the support from Maria Saheed, Bakhtawer Qureshi, Sajda Ashraf, Alamgir Khan and all the members of the $m c g$ computational group.

\section{References}

[1] Veeramachaneni G. K, Raj K. K, Chalasani L. M, Bondili J. S, Talluri V. R. (2015): High-throughput virtual screening with e-pharmacophore and molecular simulations study in the designing of pancreatic lipase inhibitors. Drug Design, Development and Therapy. 2015: 9 4397-4412.

[2] Canaan, S., Roussel, L., Verger, R. and Cambillau, C. (1999). Gastric lipase: crystal structure and activity. Biochimica et Biophysica Acta -Molecular and Cell Biology of Lipids, 1441: 197-204.

[3] Lowe, M. E. (1997). Structure and function of pancreatic lipase and colipase. Annual Review of Nutrition, 17: 141-158.

[4] Winkler, F. K., Darcy, A. and Hunziker, W. (1990). Structure of Human Pancreatic Lipase. Nature, 343; 771-774.

[5] van Tilbeurgh, H., Egloff, M. P., Martinez, C., Rugani, N., Verger, R., and Cambillau, C. (1992) Interfacial activation of the lipase-procolipase complex by mixed micelles revealed by X-ray crystallography Nature, 362, 814-420.

[6] van Tilbeurgh, H, Roussel, A., Lalouelln J., and Cambillau, C. (1994); Lipoprotein Lipase: Molecular model based on the Pancreatic Lipase X-Ray structure: Consequences for Heparin binding and catalysis, Journal of Biological Chemistry, 269 (6), 4626-4633.

[7] Freie A. B., Ferrato, F., Carrière, F., and Lowe, M. E (2006): Val407 and Ile408 in the $\beta 5$ ' Loop of Pancreatic Lipase Mediate Lipase-Colipase Interactions in the Presence of Bile Salt Micelles. Journal of Biological Chemistry, 281 (12), 7793-7800.

[8] Bauer, E., Jakob, S. and Mosenthin, R. (2005). Principles of physiology of lipid digestion. Asian -Australasian Journal of Animal Sciences, 18; 282-295.

[9] Miled, N., Canaan, S., Dupuis, L., Roussel, A., Riviere, M., Carriere, F., de Caro, A., Cambillau, C. and Verger, R. (2000). Digestive lipases: from three-dimensional structure to physiology. Biochimie, 82: 973-986.

[10] Cygler, M. and Schrag, J. D. (1997). Structure as basis for understanding interfacial properties of lipases. Methods in Enzymology, 284: 3-27.

[11] Egloff, M. P., Marguet, F., Buono, G., Verger, R., Cambillau, C. and van Tilbeurgh, H. (1995). The 2.46Ao Resolution structure of the pancreatic lipase-colipase complex inhibited by a C11 alkyl phosphonate. Biochemistry 34, 2751-2762.
[12] Egloff, M. P., Sarda, L., Verger, R., Cambillau, C., \& Tilbeurgh, H. V. (1995). Crystallographic study of the structure of colipase and of the interaction with Pancreatic lipase. Protein Science, 4 (1), 44-57.

[13] Bourne Y, Martinez C, Kerfelec B, Lombardo D, Chapus C, Cambillau C. (1994). Horse pancreatic lipase. The crystal structure refined at 2.3Ao resolution. Journal of Molecular Biology, 238 (5): 709-732.

[14] Wilde, P. J. and Chu, B. S. (2011). Interfacial and colloidal aspects of lipid digestion. Advances in Colloid and Interface Science, 165: 14-22.

[15] Brockman, H. (2002). Colipase-induced reorganization of interfaces as a regulator of lipolysis. Colloids and Surfaces B: Biointerfaces, 26: 102-111.

[16] Childers M. C and Daggett V. (2017): Insight from molecular dynamics simulations for computational protein design. Molecular System Design and Engineering. 2, 9-33.

[17] Childers, M. C, and Daggett, V. (2018): Validating Molecular Dynamics Simulations against Experimental Observables in Light of Underlying Conformational Ensembles. Journal of Physical Chemistry. B, 2018, 122 (26), 6673-6689.

[18] Aloulou, A., Frikha, F., Noiriel, A., Ali, M. B., Abousalham, A., (2014): Kinetic and structural characterization of triacylglycerol lipases possessing phospholipase A1 activity. Biochimica et Biophysica Acta, 1841: 581-587.

[19] Barbe, S., Corte', J., Sime'on, T., Monsan, P., RemaudSime' on, M., Andre', I. (2011). A mixed molecular modelingrobotics approach to investigate lipase large molecular motions. Proteins. 79 (8): 2517-29.

[20] James J. J, Lakshmi B. S, Raviprasad V, Ananth M. J, Kangueane P and Gautam P. (2003): Insights from molecular dynamics simulations into $\mathrm{pH}$-dependent enantioselective hydrolysis of ibuprofen esters by Candida rugosa lipase. Protein Engineering 16: 1017-1024.

[21] Selvan A., Seniya C., Chandrasekaran S. N., Siddharth N., Anishetty S., Pennathur G. (2010): Molecular dynamics simulations of human and dog gastric lipases: Insight into domain movements. FEEBS Letters. 584: 4599-4605.

[22] van Tilbeurgh, H., Sarda, L., Verger, R. and Cambillau, C. (1992). Structure of the pancreatic lipase-procolipase complex. Nature, 359: 159-162.

[23] Berman, H. M., Westbrook, J., Feng, Z., Gilland, G., Bhart, T. N., Weissig, H., Shindyalov, I. N and Bourne, P. E. (2000): The Protein Data Bank. Nucleic Acids Research, 28, 235-242.

[24] Berendsen, H. J. C., van der Spoel, D. and van Drunen, R. (1995): GROMACS: a message-passing parallel molecular dynamics implementation. Computational Physics Communications, 91, 43-56.

[25] Lindahl, E., Hess, B. and van der Spoel, D. (2001): GROMACS 3.0: a package for molecular simulation and trajectory analysis. Journal of Molecular Model, 7, 306-317.

[26] Kutzner, C., Páll, S., Fechner, M., Esztermann, A., Groot, B. L., Grubmüller. H. (2015): Best bang for your buck: GPU nodes for GROMACS biomolecular simulations. Journal of Computational Chemistry, 36, 1990-2008. 
[27] Berendsen, H. J. C., Grigera, J. R. and Straatsma, T. P. (1987): The missing term in effective pair potentials. Journal of Physical Chemistry. 91 (24), 6269-6271.

[28] Kaminski, G. A., Friesner, R. A., Tirado-Rives, J. and Jorgensen, W. L. (2001): Evaluation and Reparametrization of the OPLS-AA Force Field for Proteins via Comparison with Accurate Quantum Chemical Calculations on Peptides. Journal of Physical Chemistry B. 105, 6474-6487.

[29] Humphrey, W., Dalke, A. and Schulten, K. (1996) VMD: visual molecular dynamics. Journal of Molecular Graphics, 14, 33-38.

[30] Bezzine, S., Carrière, F., De Caro, J., Verger, R. and De Caro, A (1998): Human Pancreatic Lipase: An Exposed Hydrophobic Loop from the C-terminal Domain May Contribute to Interfacial Binding. Biochemistry 37, 1184611855 .

[31] Galzitskaya, O. V., Garbuzynskiy, S. O. (2006) Entropy capacity determines protein folding. Proteins, 63, 144-154.

[32] Marques, S. M., Bednar, D., and Damborsky, J. (2019): Computational Study of Protein-Ligand Unbinding for Enzyme Engineering. Frontiers in Chemistry. 6: 650.

[33] Ishak, S. N. H., Aris, S. N. A. M., Halim K. B. A., Ali, M. S.
M., Leow, T. C., Kamarudin, N. H. A, Masomian, M. and Rahman, R. N. Z. R. A (2017) Molecular Dynamic Simulation of Space and Earth-Grown Crystal Structures of Thermostable T1 Lipase Geobacillus zalihae Revealed a Better Structure. Molecules, 22, 1574.

[34] Jennens, M. L. and Lowe M. E (1994): A surface loop covering the active site of Human Pancreatic Lipase influences interfacial activation and lipid binding. Journal of Biological Chemistry, 209 (41), 25470 -25474.

[35] Withers-Martinez, C., Carrière, F., Verger, R., Bourgeois, D. and Cambillau, C. (1996) A pancreatic lipase with a phospholipase A1 activity: crystal structure of a chimeric pancreatic lipase-related protein 2 from guinea pig. Structure, 4: $1363-1374$.

[36] Takano K, Tsuchimori K, Yamagata Y, Yutani K. (2000). Contribution of salt bridges near the surface of a protein to the conformational stability. Biochemistry. 39 (40): 12375-81.

[37] Jelesarov, I. and Karshikoff, A. (2009): Defining the role of salt bridges in protein stability. Methods in Molecular Biology, $490,227-60$

[38] Pylaeva, S., Brehm, M., and Sebastiani D., (2018): Salt bridge in aqueous solution: strong structural motifs but weak enthalpic effect. Scientific Reports, (2018) 8: 13626. 